\title{
Influence of mechanical cycling in the microbiological seal and microgaps in tapered connection implants
}

\author{
Benedito Damasceno Ferreira Neto, Elizabeth Ferreira Martinez, Daiane Cristina Peruzzo, Júlio César Joly, \\ Fabiana Mantovani Gomes França, Marcelo Henrique Napimoga
}

Faculdade São Leopoldo Mandic, Instituto de Pesquisas São Leopoldo Mandic, Campinas/SP, Brazil

Correspondence Author: Marcelo H. Napimoga, Faculdade São Leopoldo Mandic, Instituto de Pesquisas São Leopoldo Mandic, Campinas/SP, Brazil.

E-mail:- marcelo.napimoga@gmail.com

Received date: 15 June 2019, Accepted date: 28 August 2019, Online date: 29 August 2019

Copyright: () 2019 Benedito Damasceno Ferreira Neto et al, This is an open-access article distributed under the terms of the Creative Commons Attribution License, which permits unrestricted use, distribution, and reproduction in any medium, provided the original author and source are credited.

\begin{abstract}
Background: This study evaluated the bacterial seal and adaptation of the abutments in a tapered connection implant system (Titaoss, Intraoss, Brazil) by means of microbiological and morphological analysis after cyclic loading. Objectives: The hypothesis of the study was to evaluate if after cycling the adaptation between abutment and implant creates gap allowing the passage of microorganisms. Methods: Twelve implants and their respective prosthetic abutments/crowns were fixed with a screw under torque of $20 \mathrm{~N}$.cm. The gap between the abutment and the implant was measured after the initial torque with the aid of a stereomicroscope and then subjected to compressive loads of $120 \mathrm{~N}$ and $2 \mathrm{~Hz}$. After cycling, a new microgap measurement was performed and the samples were immersed in Escherichia coli suspension and incubated at $37^{\circ} \mathrm{C}$. After 14 days, the prosthetic abutments were separated from the respective implants, and the presence of bacterial infiltration was evaluated. For the statistical calculations, the Student $t$ test, binomial and G tests were used at a significance level of $5 \%$. Results: The results showed that the specimens submitted to compressive load showed significantly smaller microgaps between the abutment and implant significantly than the non-cycled samples $(p=0.032)$. There was no significant difference in bacterial leakage in the implant models studied, regardless of mechanical cycling $(p=0.296)$. Conclusion: The tapered connection implant system used showed an effective bacterial seal, regardless of mechanical cycling.
\end{abstract}

Keywords: morse taper-type connection, microbiological sealing, abutment/implant connection

\section{INTRODUCTION}

Implant systems differ from each other in the geometry of the implant / abutment interface, especially between tapered and hexagonal connections. Such interface is the most vulnerable point of the entire implant-supported restoration, as it must resist constant masticatory forces as well bacterial invasion (Alves et al., 2014).

It has been observed that some connections promote greater resistance to the displacement caused by occlusal forces. Displacement of such connections has been associated with mechanical stress within the implant and consequent acceleration of marginal bone loss (Kitagawa et al., 2005; Quaresma et al., 2008). In addition, the lack of stability of a connection causes displacement between the abutment and the implant, resulting in micromovements and consequently remodeling of the more cervical bone portions, with posterior tissue loss and marginal bone defect (Maeda et al., 2006). In addition, loosening or screw fracture, and consequent implant failure may occur.

It is believed that internal tapered connection system presents only minute gaps between the prosthetic abutment and the implant, which minimizes bacterial colonization (Tesmer et al., 2009; Merz et al., 2000). This advantage is expected because tapered components, especially of the Morse type, promote an intimate adaptation between the superimposed surfaces, acquiring mechanical resistance similar to that of a single solid piece. The tightening action is due to intimate contact and mechanical friction locking between the components, generating a cold weld-like bond between them. In order for this to occur, however, the Morse locking must have an angulation between 2 and 4 degrees and a fully friction locking interface without a screw (Carvalho et al., 2009).

Although tapered connections do not promote an absolute seal, it has been suggested that they are more effective at preventing bacterial leakage than conventional connections due to less displacement of the prosthetic abutment and by promoting less tension on the retention screw of the component (Schmitt et al., 2014). A recent study has shown, however, that the cross- 
sectional circularity of tapered connections may carry minute imperfections, which means that after torque, the prosthetic abutment may move away from the circularity error, opening a considerable space on the opposite end the defect (Lopes de Chaves E Mello Dias et al., 2018).

In a previous study conducted by Costa et al. (2017), Titaoss ${ }^{\circledR}$ tapered implants (Intraoss), without the effect of mechanical cycling, were able to avoid bacterial leakage in vitro and showed superior results when compared to external hexagonal abutments. Therefore, in this study, mechanical force was applied simulating masticatory forces, in order to evaluate the bacterial sealing ability and maladjustment between the prosthetic abutment and the internal tapered connection implant.

\section{MATERIALS AND METHODS}

Twelve implants of internal tapered connection measuring $4.0 \mathrm{~mm}$ in diameter and $11 \mathrm{~mm}$ in length with $11.5^{\circ}$ angulation (TitaOss Max®, IntraOss, Brazil), and their respective indexed prosthetic abutments (CMN 2.5 mm) were evaluated. The specimens were activated with an insertion torque of $20 \mathrm{~N} . \mathrm{cm}$ according to the manufacturer's instructions. For a closer simulation of clinical behavior, chrome-cobalt cast crowns were made based on the anatomy of the first maxillary molar (Figure 1). The materials used in this study (implants, prosthetic components and torque wrench) were provided by the manufacturers with no conflict of interests.

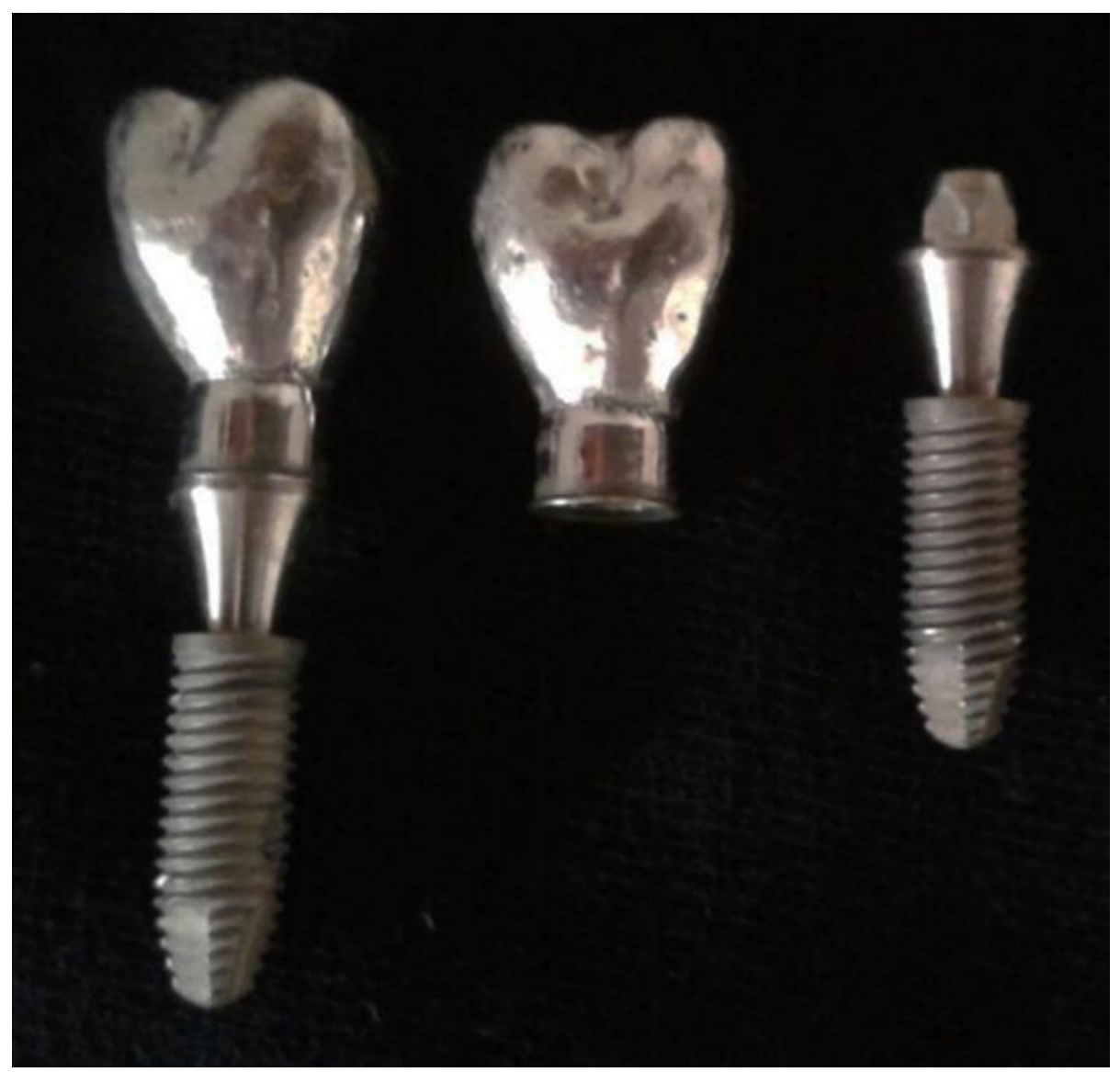

Figure 1: Implants, prosthetic components and torque wrench were provided by IntraOss (Brazil). Chrome-cobalt cast crowns were made based on the anatomy of the first maxillary molar.

Marginal maladjustment was assessed under stereomicroscopy (Microdurometro Pantec, Campinas, SP, Brazil) at four random points (mesial, distal, vestibular and lingual) around the implant platform near the interface of the prosthetic abutment and the mean microgap values from each group was calculated. Measurements were performed by a single calibrated operator. Of the 12 abutment / implant sets, 6 were randomly separated using the randomization platform (https://www.random.org/) and subjected to 500,000 compression cycles of $120 \mathrm{~N}$ and $2 \mathrm{~Hz}$ at an angle of $30^{\circ}$ with the long axis of the implant, according to technical standards recommended by ISO 14801: 2007 and previously described (Alves et al., 2016). After completion of cycling, all 12 abutment / implant assemblies (cycled and non-cycled) were sterilized in ethylene oxide for further experiments.

All procedures for bacterial sealing analysis were performed inside a disinfected laminar flow hood and covered with a sterile field. The operator was blind to the group to which each set belonged.

The implant-abutment/crown specimens were immersed in $5 \mathrm{ml}$ of E. coli suspension at a concentration of $15 \mathrm{x} 10^{8} \mathrm{CFU} / \mathrm{ml}$, McFarland 5 scale (Probac do Brazil, São Paulo, SP, Brazil) and incubated for 14 days at $37^{\circ} \mathrm{C}$ under aerobic conditions, with the culture medium changed every $48 \mathrm{~h}$. To ensure that the external portion of the connection was not contaminated, prior to implant immersion, each set was swabbed around the entire connection circumference with a microbrush moistened in $0.9 \%$ saline. Each microbrush was also immersed in Brain Heart Infusion (BHI, Himedia, Mumbai, India) culture medium, serving as control for 
external contamination (Alves et al., 2014; Peruzetto et al., 2016). All tubes were duly identified and kept upright in a bacteriological incubator for 14 days at $37^{\circ} \mathrm{C}$ under aerobic conditions, and the culture medium changed every $48 \mathrm{~h}$. At $24 \mathrm{~h}$, the tubes were monitored for evidence of bacterial growth, which macroscopically, is characterized by turbidity of the culture broth or deposits at the bottom of the tubes, indicating the inability of the implant-abutment connection to prevent the passage of bacteria from the outer to the inner aspect of the implant from each sample with suspected contamination, aliquots of the culture medium within in the tube $(10 \mu \mathrm{l})$ were plated onto $\mathrm{BHI}$ agar and incubated at $37^{\circ} \mathrm{C}$ for $24 \mathrm{~h}$ and recorded to confirm visual macroscopic evidence of bacterial growth. After contamination, the implant-abutment/crown assemblies were subjected to external decontamination using $17 \%$ paracetic acid and gauze swab, which were rubbed against the implant for 20s.

\section{Statistical analysis}

The data regarding maladaptation in the tapered connection implant assemblies were evaluated for normality and homogeneity of variance and were then analyzed using the Student t-test and binomial and G tests were used at a significance level of $5 \%$ for independent samples to analyze the influence of mechanical cycling.

To investigate whether sealing was affected by mechanical cycling, the binomial test was applied. Statistical calculations were performed on SPSS 23 (SPSS Inc., Chicago, IL, USA) at a significance level of $5 \%$.

\section{RESULTS}

The Student t-test for independent samples indicated that the sets of implants submitted to mechanical cycling had significantly lower maladaptation than the non-cycled samples $(\mathrm{p}=0.032)$, as shown in Figure 2 . The minimum and maximum microgap values between the sets after cycling were 4.92 and $6.81 \mu \mathrm{m}$, whereas the non-cycled group yielded microgaps ranging from 6.75 and $8.11 \mu \mathrm{m}$.

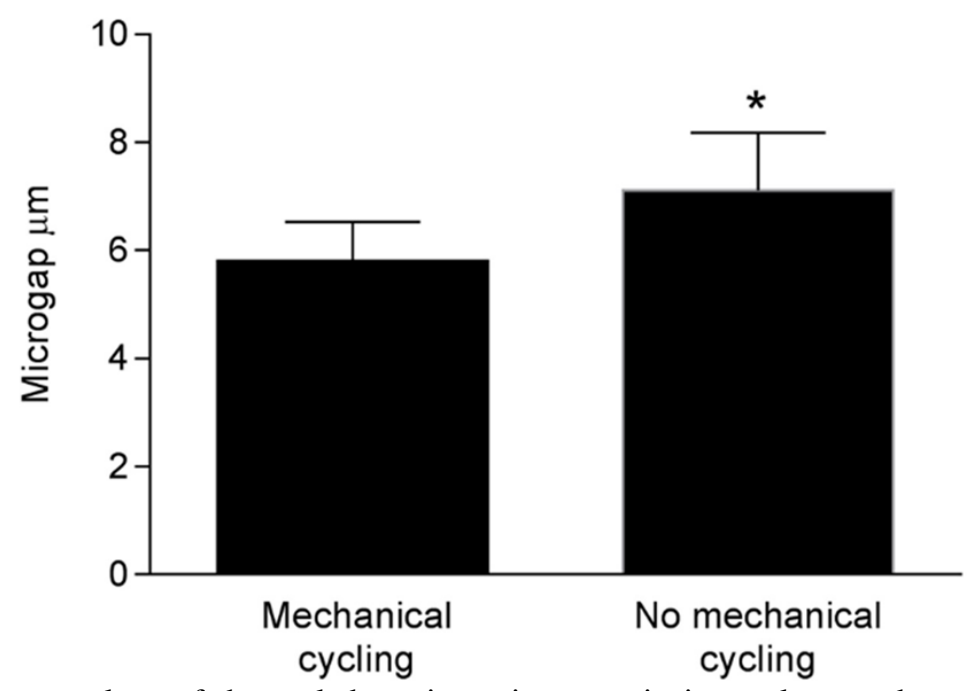

Figure 2: Bar chart of the mean values of the maladaptation microgaps in internal tapered connection implant sets with and without mechanical cycling. The results indicated that the sets of implants submitted to mechanical cycling had significantly lower maladaptation than the non-cycled samples $(\mathrm{p}=0.032)$.

The microbiological results revealed that only one of the six samples (16.7\%) that underwent mechanical cycling had E. coli contamination, whereas the group not submitted to cycling had no contaminated samples (Figure 3). The binomial test, however, showed no significant difference between the groups with or without mechanical cycling $(\mathrm{p}=0.296)$. 


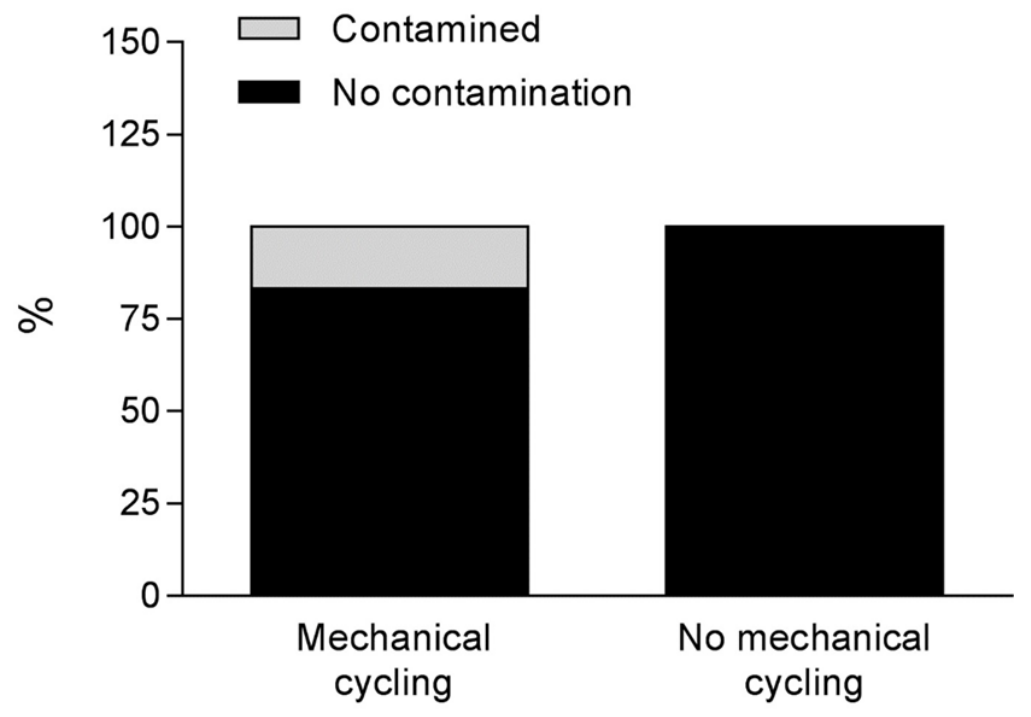

Figure 3: Bar chart of the proportion of contaminated media when the tapered connection implant sets, with or without mechanical cycling, were immersed in a suspension of Escherichia coli. The microbiological results revealed no statistical difference between the groups $(\mathrm{p}=0.0296)$.

\section{DISCUSSION}

In this in vitro study, the effect of cycling loading on the microbial sealing potential and the presence of microgaps in the implant-abutment interface of tapered connection implant systems with an angulation of 11.5 were evaluated. A previous report (Costa et al., 2017) demonstrated an effective seal of such connection without mechanical cycling. The results of the present study showed that after mechanical cycling, the implant/abutment ensemble showed significantly fewer microgaps than the non-cycled samples, though no significant difference was observed between the cycled and non-cycled groups in terms of microbial sealing.

The potential colonization of the inner aspect of the connection through the microgaps is related to numerous biological and functional conditions of the system, the torque used to connect the components (gross et al., 1999), the loading forces when the implant is in function and the accuracy between the implant components (Tesmer et al., 2009; Steinebrunner et al., 2005), which is extremely important for the long-term success of implant-supported dental rehabilitations. In a very recent report (Lopes de Chaves E Mello Dias et al., 2018), it has been demonstrated conformational irregularities within the implant connection at the prosthetic abutment site, translating into microgaps on one side of a longitudinal section of the abutment-implant interface and consequent microbiological contamination within the system. In addition to this, the incidence of occlusal forces may lead to reduction of the preload, favoring unscrewing of the prosthetic abutment, thus facilitating the penetration of bacteria along the microgaps (Steinebrunner et al., 2005; Koutouzis et al., 2011; Baggi et al., 2013) and, consequently, marginal bone loss (Hermann et al., 2001; Dias et al., 2012).

Considering the potential fragility of the system when subjected to functional loads, the present study simulated a 6-month clinical situation of the implant / abutment in function. The results showed microgaps with minimum and maximum dimensions of 4.92 and $6.81 \mu \mathrm{m}$, respectively, for samples submitted to cyclic loading whereas for the group not submitted to mechanical cycling, these values varied between 6.75 and $8.11 \mu \mathrm{m}$. Such findings support the hypothesis that tapered connections may reduce or even eliminate microgaps, depending on the standard or quality of the machining and finishing of the parts.

Implants with internal tapered connection tend to maintain the connection between the abutment / implant joint away from the bone crest, with greater stability of its components (Canullo et al., 2015). The microbiological results showed that $16.7 \%$ of specimens submitted to mechanical cycling had E. coli contamination, whereas in the group not submitted to cyclic loading, no contamination was detected. Although no significant difference was observed between the evaluated groups, the findings nonetheless show that when axial forces are applied, the microbial seal fails. Although cyclic loading increased the bond between the abutment and the implant, as evidenced by the lower microgaps values at the evaluated points, an increase of the space in one or more surfaces of the specimens probably occurs due to micromovements of the abutment, thus allowing contamination, which could be explained by a possible internal circularity error (Lopes de Chaves E Mello Dias et al., 2018).

Some studies have highlighted the superiority and behavior predictability of tapered connections when subjected to axial and lateral loads, which remain stable in the long term (Merz et al., 2000; Bozkaya and Müftü, 2005; Mangano et al., 2009; Sannino and Barlattani, 2013) when compared to hexagonal connections. The literature, however, has highlighted the issue of bacterial infiltration through the implant / abutment interface among the different tapered connection systems (Do Nascimento et al., 2012; Baggi et al., 2013; Aguirrebeitia et al., 2013; Alves et al., 2014; Alves et al., 2016). In conclusion, all samples showed an effective bacterial seal, regardless of mechanical cycling. 
Citation: Benedito Damasceno Ferreira Neto, et al., Influence of mechanical cycling in the microbiological seal and microgaps in tapered connection implants. Australian Journal of Basic and Applied Sciences, 13(8): 48-53. DOI: 10.22587/ajbas.2019.13.8.7

\section{FUNDING}

This work was supported by CAPES and Research Productivity Fellowship to MHN, FMGF and EFM from CNPq.

\section{ACKNOWLEDGMENTS}

The authors wish to thank Gilca Saba for her excellent technical support.

\section{COMPETING INTERESTS}

The authors declare that they have no competing interests.

\section{REFERENCES}

Aguirrebeitia, J., Abasolo, M., Vallejo, J., and Ansola, R. 2013. Dental implants with conical implant-abutment interface: influence of the conical angle difference on the mechanical behavior of the implant. The International Journal of Oral \& Maxillofacial Implants, 28(2):e72-82. DOI: 10.11607/jomi.2775

Alves, D. C. C., Carvalho, P. S. P., and Martinez, E. F. 2014. In vitro microbiological analysis of bacterial seal at the implantabutment interface using two Morse taper implant models. Brazilian Dental Journal, 25: 48-53. DOI: 10.1590/01036440201600604

Alves, D. C. C., de Carvalho, P. S. P., Elias, C. N., Vedovatto, E., and Martinez, E. F. 2016. In vitro analysis of the microbiological sealing of tapered implants after mechanical cycling. Clinical Oral Investigations, 20:2437-2445. DOI: 10.1007/s00784-016-1744-0.

Baggi, L., Di Girolamo, M., Mirisola, C., and Calcaterra, R. 2013. Microbiological evaluation of bacterial and mycotic seal in implant systems with different implant-abutment interfaces and closing torque values. Implant Dentistry, 22(4):344-350. DOI: 10.1097/ID.0b013e3182943062

Bozkaya, D., and Müftü, S. 2005. Mechanics of the taper integrated screwed-in (TIS) abutments used in dental implants. Journal of Biomechanics, 38:87-97. DOI: 10.1016/j.jbiomech.2004.03.006

Canullo, L., Penarrocha-Oltra, D., Soldini, C., Mazzocco, F., Penarrocha, M., and Covani, U. 2015. Microbiological assessment of the implant-abutment interface in different connections: cross-sectional study after 5 years of functional loading. Clinical Oral Investigations, 26:426-434. DOI: 10.1111/clr.12383.

Carvalho, P. S. P., Pellizzer, E. P., Verri, F. R., Falcón-Antenucci, R. M., and Noritomi, P. Y. 2009. A visão biomecânica dos implantes de encaixe externo e interno. In Osseointegração: Visão contemporânea da Implantodontia. São Paulo: Quintessence, 165-183.

Costa, G. N., Martinez, E. F., Ruellas, A. M., Peruzzo, D. C., Joly, J. C., and Napimoga, M. H. 2017. Microbiological Sealing Analysis of a Tapered Connection and External Hexagon System. International Journal of Dentistry, 3849085. DOI: $10.1155 / 2017 / 3849085$.

Dias, E. C., Bisognin, E. D., Harari, N. D., Machado, S. J., da Silva, C. P., Soares, G. D., and Vidigal, G. M Jr. 2012. Evaluation of Implant-abutment microgap and bacterial leakage in five external-hex implant systems: an in vitro study. The International Journal of Oral \& Maxillofacial Implants, 27:346-351.

Do Nascimento, C., Miani, P. K., Pedrazzi, V., Gonçalves, R. B., Ribeiro, R. F., Faria, A. C., Macedo, A. P., and de Albuquerque, R. F Jr. 2012. Leakage of saliva through the implant-abutment interface: in vitro evaluation of three different implant connections under unloaded and loaded conditions. The International Journal of Oral \& Maxillofacial Implants, 27(3):551560.

Gross, M., Abramovich, I., and Weiss, E. I. 1999. Microleakage at the abutment-implant interface of osseointegrated implants: a comparative study. The International Journal of Oral \& Maxillofacial Implants, 14(1):94-100.

Hermann, J. S., Schoolfield, J. D., Schenk, R. K., Buser, D., and Cochran, D. L. 2001. Influence of the size of the microgap on crestal bone changes around titanium implants. A histometric evaluation of unloaded non-submerged implants in the canine mandible. Journal of Periodontology, 72:1372-1383. DOI: 10.1902/jop.2001.72.10.1372

Kitagawa, T., Tanimoto, Y., Odaki, M., Nemoto, K., and Aida, M. 2005. Influence of implant/abutment joint designs on abutment screw loosening in a dental implant system. Journal of Biomedical Materials Research Part B, 75:457-463. DOI: 10.1002/jbm.b.30328

Koutouzis, T., Wallet, S., Calderon, N., and Lundgren, T. 2011. Bacterial colonization of the implant-abutment interface using an in vitro dynamic loading model. Journal of Periodontology, 82(4):613-618. DOI: 10.1902/jop.2010.100415.

Lopes de Chaves E Mello Dias, E. C., Sperandio, M., and Napimoga, M. H. 2018. Association Between Implant-Abutment Microgap and Implant Circularity to Bacterial Leakage: An In Vitro Study Using Tapered Connection Implants. The International Journal of Oral \& Maxillofacial Implants, 33(3):505-511. DOI: 10.11607/jomi.5836.

Maeda, Y., Satoh, T., Sogo, M. 2006. In vitro differences of stress concentrations for internal and external hex implant-abutment connections: a short communication. Journal of Oral Rehabilitation, 33:75-78. DOI: 10.1111/j.1365-2842.2006.01545.x

Mangano, C., Mangano, F., Piattelli, A., Iezzi, G., Mangano, A., La Colla, L. 2009. Prospective clinical evaluation of 1920 Morse taper connection implants: results after 4 years of functional loading. Clinical Oral Implants Research, 20(3):254-261. DOI: 10.1111/j.1600-0501.2008.01649.x. 
Merz, B. R., Hunenbart, S., Belser, U. C. 2000. Mechanics of the implant-abutment connection: an 8-degree taper compared to a butt joint connection. The International Journal of Oral \& Maxillofacial Implants, 15:519-526.

Peruzetto, W. M., Martinez, E. F., Peruzzo, D. C., Joly, J. C., and Napimoga, M. H. 2016. Microbiological Seal of Two Types of Tapered Implant Connections. Brazilian Dental Journal, 27(3):273-277. DOI: 10.1590/0103-6440201600604.

Quaresma, S. E., Cury, P. R., Sendyk, W. R., and Sendyk, C. (2008) A finite element analysis of two different dental implants: stress distribution in the prosthesis, abutment, implant, and supporting bone. Journal of Oral Implantology, 34(1):1-6. DOI: $10.1563 / 1548-1336$

Sannino, G., and Barlattani, A. 2013. Mechanical evaluation of an implant-abutment self-locking taper connection: finite element analysis and experimental tests. The International Journal of Oral \& Maxillofacial Implants, 28(1):e17-26. DOI: 10.11607/jomi.2058

Schmitt, C. M., Nogueira-Filho, G., Tenenbaum, H. C., Lai, J. Y., Brito, C., Döring, H., Nonhoff, J. 2014. Performance of conical abutment (Morse Taper) connection implants: a systematic review. Journal of Biomedical Materials Research Part A, 102(2):552-574. DOI: 10.1002/jbm.a.34709

Steinebrunner, L., Wolfart, S., Bossmann, K., and Kern, M. 2005. In vitro evaluation of bacterial leakage along the implantabutment interface of different implant systems. The International Journal of Oral \& Maxillofacial Implants, 20(6):875-881.

Tesmer, M., Wallet, S., Koutouzis, T., and Lundgren, T. 2009. Bacterial colonization of the dental implant fixture-abutment interface: an in vitro study. Journal of Periodontology, 80:1991-1997. DOI: 10.1902/jop.2009.090178 